\title{
LEADING AND SUSTAINING ZIMBABWE'S PRIVATE SCHOOLS: MATCHING VISION WITH ECONOMIC REALITY
}

\begin{abstract}
The political, economic and social challenges in Zimbabwe are well documented. Public schools have been damaged by a shortage of resources, and by a brain drain of teachers. This has led many parents to seek private education for their children but the country's economic problems mean that they often cannot afford to pay the fees. This demanding context informed the authors' study of leadership in twelve private schools in Harare and the surrounding area. Individual and focus group interviews were conducted with 19 leaders in these schools. The findings show that most of the schools have experienced significant falls in student numbers, despite cutting fees. This creates a severe management challenge for principals, other leaders, and school owners. There have been redundancies at several of the schools, which the leaders find stressful, while salary levels remain modest, although still higher than those in the public sector. The infrastructure and facilities are generally good compared to those in the public sector but leaders lament that they cannot be enhanced in the current financial climate. Most of the schools have a distinctive Christian ethos, and a vision to provide the best possible education for their children, but the leaders' ambitious plans are thwarted by Zimbabwe's harsh economic realities.
\end{abstract}

\section{Key Words}

Christian education, principals, private schools, vision, Zimbabwe

\section{Introduction}

The political, economic and social challenges facing Zimbabwean society are well documented (Moyo 2014) and they impact on education as well as other public services. Education in Zimbabwe is often regarded as one of the best in Africa. Chiome and Paul (2011) report that, in 2010, Zimbabwe had the highest literacy rate in Africa, at 92\%, compared to Tunisia, the previous leader, with $87 \%$. 'The achievement is despite the country's education sector suffering from brain drain and lack of resources . . . when the economy was razed by hyperinflation' (ibid: 1143), leading Mupa and Chinooneka (2015) to claim that there is 'decay' in Zimbabwean schools. One of the consequences of these economic problems was a severe shortage of text books, reported as no better than one in 15 (Zimeye, 2009). Even more serious was an ongoing teachers' strike, which led to some schools going two years without teaching (ibid). The then Minister of Education, Sport, Arts and Culture, David Coltart, commented that, when taking office, he found the education sector 'in a calamitous state' (ibid). 'Zimbabwe's education 
sector, once a model in Africa, continues to be riddled with serious challenges' (ibid). Zikhali and Perumal (2016) comment on the impact of these socio-economic conditions on children's physical, emotional, social and educational development. Moyo (2014) reports that the public has lost confidence and trust in state institutional architecture, including education, where corruption is endemic. These factors combined to lead parents to seek alternative schooling for their children, including private Christian schools. The Christian ethos is welcome because it may be seen to offer a stronger sense of moral purpose. Private education is preferred because it avoids the problems of teacher strikes, inadequate resources, and public sector bureaucracy and corruption, reported above. As recently as 2010, Mapfumo (2010) reported that private schools were booming in Zimbabwe. In a review of Southern Africa, including Zimbabwe, Day et al (2014: 19) claim that teaching is better in private schools than in their state equivalents:

'Teaching in private schools tends to be better -in terms of more teacher presence and teaching activity, and teaching approaches that are more likely to lead to improved outcomes - than in state schools ... [This may be] due to increased accountability of teachers to employers in private schools. However, much of the evidence reviewed also indicates that private school teachers are often less formally qualified, have low salaries and weak job security; such conditions might in part explain the greater teacher effort in private schools'.

Regardless of the relative merits of the two sectors, Zimbabwe's economic problems mean that most parents cannot afford private education for their children. This creates a severe management challenge for principals, other leaders, and school owners, notably in respect of falling student numbers, arising from weak recruitment of students and retention difficulties, even with reductions in fee levels. These considerations provide the background to the authors' study of leadership in private Christian schools in Harare and the surrounding area. The paper focuses on participants' satisfaction levels in this challenging climate and on the impact of Zimbabwe's economic problems on leadership and management in private schools.

\section{$\underline{\text { Moral leadership }}$}

The impact of the economic challenges on the management of Zimbabwe's Christian private schools created certain moral dilemmas for school leaders. The concept of moral leadership thus provides the theoretical framework for this paper. The moral leadership model assumes that the critical focus of leadership ought to be on the values, beliefs and ethics of leaders themselves. Authority and influence are to be derived from defensible conceptions of what is right or good (Leithwood, Jantzi and Steinbach, 1999: 10). Moral leadership is underpinned strongly by leaders' values. The model assumes that 
leaders act with integrity, drawing on firmly held personal and professional values. These serve to inform the school's vision and mission, and to underpin decision-making.

West-Burnham (1997: 239) discusses two approaches to leadership which may be categorized as 'moral'. The first he describes as 'spiritual' and relates to 'the recognition that many leaders possess what might be called ' 'higher order' perspectives', perhaps represented by a particular religious affiliation. Woods's (2007: 148) survey of headteachers in England found that 52\% 'were inspired or supported in their leadership by some kind of spiritual power'. West-Burnham's (1997: 241) second category is 'moral confidence', the capacity to act in a way that is consistent with an ethical system and is consistent over time.

Drawing on data from secondary schools in Queensland, Australia, Keddie (2016) argues that morally focused leadership engages with a broad view of the purposes of education, not solely concerned with test scores. This leads to the notion of moral purpose (Bezzina 2012: 250), 'a commitment to ends that express underlying values and ethics'. Rintoul and Goulais (2010) refer to the moral 'dilemmas' faced by vice-principals in Ontario, Canada, a concept that is apposite for the challenges facing the Zimbabwean leaders.

Sergiovanni (1991: 329) notes the potential for tension between moral and managerial leadership:

'In the principalship, the challenge of leadership is to make peace with two competing imperatives, the managerial and the moral. The two imperatives are unavoidable and the neglect of either creates problems. Schools must be run effectively if they are to survive . . But for the school to transform itself into an institution, a learning community must emerge ... [This] is the moral imperative that principals face'.

The research participants encountered severe challenges to the values underpinning their faith, arising from the economic crisis in Zimbabwe, and experienced tensions in addressing such challenges. This constitutes the problem explored through the authors' study of leadership in private Christian schools in Harare and the surrounding area, leading to four research questions:

1. What are the most satisfying aspects of participants' current leadership role?

2. What are the least satisfying aspects of participants' current leadership role?

3. What is the impact of Zimbabwe's economic problems on leadership and management in private schools?

4. How do school leaders respond to falling student numbers? 


\section{Methods and Sampling}

The research approach was qualitative and exploratory, given the limited previous research on leadership in Zimbabwe's Christian private schools. The authors used purposive and convenience sampling to identify head teachers in private schools ${ }^{1}$ in Harare and the surrounding areas. The sample mainly comprised faith schools, from different Christian denominations. Where the head teacher was not available, another senior teacher was interviewed. In certain settings, more than one participant was interviewed, either in separate individual interviews, or as a focus group. In total, there were 19 participants, at 12 schools (see table 1).

\begin{tabular}{|l|l|l|}
\hline School identifier & School type & Student numbers \\
\hline B & Secondary & 495 \\
\hline C & Secondary & 135 \\
\hline CM & Secondary & 181 \\
\hline E & Secondary & 211 \\
\hline F & Secondary & 219 \\
\hline G & Primary & 450 \\
\hline M & Secondary & 123 \\
\hline S & Secondary & 131 \\
\hline SP & Primary & 558 \\
\hline T & Secondary & 600 \\
\hline TP & Primary & 300 \\
\hline TS & & \\
\hline
\end{tabular}

\section{Table 1: School sample}

The research team conducted 14 individual interviews and two focus group interviews (one with two leaders, and one with three). The authors prepared an interview guide linked to the research questions.

${ }^{1}$ The Zimbabwe Ministry of Education declined permission to access public schools 
The questions were mostly broad and open, reflecting the exploratory nature of the research. The interviews were all conducted at the participants' schools, typically in their offices, and lasted between 45 and 60 minutes. These qualitative data were analysed thematically. Some themes were derived from the research questions but others emerged from the data.

Before conducting the study, ethical approval was secured from the principal investigator's university. The leaders were asked to provide their voluntary informed consent to take part in the study, and all agreed to do so. The sample was overwhelmingly male, with only three female participants, two of whom were in subordinate roles. This imbalance was reinforced through the use of gendered language, such as head master, and senior master. Zikhali and Perumal's (2016: 355) study of 12 female Zimbabwean heads shows stereotypical gendered expectations that women are perceived to be 'less legitimate as leaders than men'. Chabaya et al (2009: 235) also found that gender stereotypes were one of the major causes of persistent under-representation of women in primary school headship. The influence of gender role stereotypes was manifest in the form of low self-esteem, lack of confidence, perceptions that their role in the family overrides all other roles, and lack of support from the home and the workplace.

The roles ${ }^{2}$ of the 19 participants in the current study are shown in table 2:

\begin{tabular}{|l|l|}
\hline Participants' roles & Number of participants \\
\hline Head teachers & Eight \\
\hline Acting heads & Two \\
\hline Deputy heads & Four \\
\hline Director of studies & Two \\
\hline Senior teacher & One \\
\hline Schools' director & One \\
\hline Owner and director & One \\
\hline
\end{tabular}

Table 2: Current roles of interviewees

\footnotetext{
${ }^{2}$ Participants' titles varied but generic terms are used to preserve confidentiality
} 
The thematic discussion below draws on findings from the research, linked to previous literature and research. The authors conducted a review of articles on school leadership in Zimbabwe, identified through the search engines of two UK universities, Google Scholar, Academic Research International, and the Zimbabwe Journal of Educational Research. A total of 420 articles were considered and 81 were used in the initial review which underpins the paper. The discussion links the authors' findings to previous research and literature on school leadership in Zimbabwe.

The first part of the discussion below distinguishes between satisfying and disappointing aspects of participants' roles as leaders of private schools.

\section{Role Satisfaction}

Although there are some frustrations (see below), almost all of the participants expressed pleasure at many aspects of their role. Significantly, it is the professional aspects of their role that create the most satisfaction. These may be classified into four themes:

\section{Classroom practice}

Almost all participants have a teaching background. Many continue to teach and express pleasure at their classroom work. The head of school CM says that "the part I enjoy most is lesson delivery. I do have a passion for my subject, Biology'. The heads of schools SP and TS make a similar point, as does the head of school M, who expresses that 'the job of teaching, to me, is a calling. So, I would rather keep in touch. I always want to have a class, so I have some teaching'. He also enjoys 'seeing a child through school'. The head of school $\mathrm{T}$ enjoys working as a teacher and providing quality education to the previously 'rejected' students served by his school. The owner of school B is 'hands on' and enjoys teaching his subject. The acting head of school E enjoys teaching and continues to teach for 16 periods a week. He acknowledges the conflict between teaching and management, but claims to have the resilience to deal with this. The decision to continue teaching may also be influenced by the economic problems facing most of the schools, in that this may mean that one fewer teacher is required (see below).

\section{Instructional leadership}

Most of the leaders have an active approach to instructional leadership, to include monitoring and classroom observation, with feedback. The head of CM, for example, outlines the process at his school, which includes assessing test results, and use of a supervision instrument for classroom observation, followed by dialogue with teachers, to discuss strengths and weaknesses, as part of 'lesson analysis'. The supervision process also includes feedback from pupils. A similar approach is adopted by the heads of 
school SP and school G. The director of studies at school S also observes teaching but she stresses that this is not 'inspection', and she provides constructive feedback to the teachers. The head of school TP monitors children's workbooks and conducts lesson observations. The head of school TS also carries out 'clinical supervision of classroom practice'. He reviews exercise books, and conducts classroom observations, at least once a term, with feedback. He adds that HoDs also observe classrooms. Similarly, at school F, clinical supervision (classroom observation and feedback) is carried out by the head, deputy head, and HoDs. The deputy head noted that:

'We do some lesson observations and we also do some checking of pupils' exercise books, to assess the quality and quantity of work. This is followed by professional development meetings, where we help each other with areas that need attention, so that we improve lesson delivery and the whole learning process'.

As noted earlier, most of the leaders in our sample began their careers in the public sector and it appears that they developed their instructional leadership skills during this period. Masuku's (2011) qualitative research in public high schools in the Midlands province provides evidence of long-term and short-term dimensions. The long-term instructional leadership dimension comprises: visioning, communication of the school vision, value management, professional development of staff, and empowerment. The shortterm instructional leadership dimension includes his or her perception of stakeholders, task or people orientation, personality, knowledge and experience, value system and trust in followers. The present research suggests a stronger focus on the short-term, notably in monitoring classroom practice.

The involvement of other senior and middle leaders in 'clinical supervision' at schools TD and F suggests a distributed approach to instructional leadership. However, Wadesango et al's (2012: 265) research in the Gweru district indicates that teacher participation in decision-making in Zimbabwean schools is insignificant, although this study was conducted in public schools. These authors report that heads sometimes make unilateral decisions and impose them on teachers for implementation, suggesting solo rather than distributed leadership.

\section{Teacher development}

Several participants refer to teacher development as one of the satisfying aspects of their work. The head of school T, for example, enjoys encouraging subordinates to undertake $\mathrm{CPD}$, for example, short courses such as ICT, QTS, and classroom delivery. He reported that:

'We have been training through the British Council. They offer refresher courses that are focused on the attributes we want to teach our learners, for education to be useful, for education to be 
contextual. We need training in particular teaching methods to teach, for example, critical thinking, collaboration, communication, digital literacy, and technology'.

Similarly, the head of school B gains satisfaction from providing in-service training for teachers, notably in respect of classroom management. The value of classroom management training is also highlighted by Korb, Seilzing-Musa and Skinner-Bonat (2016).

\section{Autonomy}

Having sufficient scope to manage the school, without undue interference in operational matters, is highly prized by some of the participants. The director of studies at school S stresses satisfaction from a high degree of autonomy, a view shared by the head of school TP, who has a supportive board, which 'does not interfere'. He 'wants the freedom to run the school'. The head of TS also enjoys autonomy from his board:

'On the admin side, I head the school. I'm quite free in a sense because I choose my own staff, my own teachers, my drivers, security, secretaries. So, this job is more of a CEO, manager than a school head. I'm into HR and labour issues, which are not strictly education, but you've got to do it. I'm into accounting and finance'

\section{Other satisfying aspects of the role}

The participants also mentioned several other enjoyable features of their work. The head of school G derives satisfaction from being innovative, for example in respect of technology and creativity. He also enjoys interacting with teachers, including classroom observations, planning, developing shared values and vision, and interacting with parents. He also believes that the appearance of the school is important ('enchanting on the eye') and is pleased with ICT development in the classroom (every teacher has a laptop). The head of school C says that 'I love my job', particularly the Christian curriculum, and seeing children through to higher education. The head of TP says that his 'first love' is education and he wants to develop a 'total person', through an academic and sporting curriculum. He enjoys contact with learners and hosts 'HM tea' with 'good students'. He also enjoys sport, and internationalization, including student exchanges. The acting head of school E enjoys 'problem solving'. Significantly, there are no links between the economy and satisfaction. Rather, this is a source of great dissatisfaction, as seen in the next section.

\section{Role Dissatisfaction}

\section{Finance}


A few of the participants, notably the head of school G, and the owner of school B, enjoy all aspects of their role but most express their disappointment with certain features, notably the impact of the economy on student recruitment and retention, and the associated financial management challenges. School rolls were falling in almost all of the 12 schools, as rising unemployment made it more difficult to recruit and retain students, even though there was a positive orientation towards private education among parents, and widespread public dissatisfaction with the public sector, as noted above. For example, school CM has only 181 students, with a capacity of 450 , and 300 students on roll as recently as 2014 . The acting head attributes declining numbers to the country's economic problems. Similarly, school C has 135 students with a capacity of 250 . High school S has 131 students with a 'comfortable' capacity of 350 , and a peak enrolment in 2009 of 648 . These private sector schools all charge fees but most reported fee reductions in response to the challenging Zimbabwe economy.

Pedzisai and Tsvere (2013) report on non-payment of fees in the Gokwe South District of Zimbabwe, drawing on data from 180 participants in six schools. They note that parents and guardians struggle to pay tuition fees and levies, as well as other costs such as uniforms and stationery. Non-payment led to school development projects being stalled and to a shortage of learning materials, leading to low morale among students and teachers, and student dropout. Similarly, the decline in fee income in the present researchers' sampled schools, linked to falling student numbers, led to tough decisions about facilities and teacher salaries. The schools' director, for example, does not like his poor facilities, which he attributes to the declining Zimbabwean economy. The acting head of school CM says that a major challenge is marketing, to address declining enrolments. The principal of school $\mathrm{C}$ says that the weak economy is a challenge. She does not enjoy it if teachers cannot be retained because of unstable economic conditions, or when parents cannot pay their fees. The director of studies at school S does not enjoy having to retrench teachers, linked to non-payment of fees. The head of TP is concerned about finance and ensuring that fees are paid on time. Similarly, the head of TS does not enjoy the macro-economic challenges, which may lead to late payment of fees. He also does not enjoy making 'hard decisions', for example to retrench teachers if student enrolment falls. The head of school F says that he does not enjoy working under pressure, as parents find it difficult to pay fees. Given the Christian ethos of this school, he noted the emotional and mental health stresses arising from this situation:

'People come all the time and you get news, some of which will be emotionally destabilising, some of which will be sorrowful and you have to live with all that, you can imagine. Naturally we emphasise but when you see that happen time and again it can take a toll on your health when you think of how best you can help because a parent may lose a job and will come and tell you that they want their child here but can no longer afford the fees. That's stressful on its own. You 
know the child very well and you know where they are headed for and you can't imagine losing them. And the child does not want to leave. They come and say "please convince my parents. I can't imagine going to public school"',

The schools' director is also concerned about low teacher salaries, and states that more than $\$ 400$ a month is required to 'make them happy'. While this figure appears to be modest, it contrasts favourably with salaries in the public sector, reported by Chiome and Paul (2011) to be as little as $\$ 150$, the lowest monthly salary in Southern Africa (ibid). This also leads to teachers offering 'extra lessons', often during school time, but for additional payment (Simbarahse and Edlight 2011).

Mavundutse et al's (2013: 303) research in 'resettlement' schools, established on land formerly owned by white farmers, shows that teachers expressed 'desperation' arising from resource shortages and this was confirmed through researchers' observations of lessons being taught without textbooks, charts and media. The limited resources were attributed to lack of funding. This was compounded by poor infrastructure. The combined effect of weak infrastructure and very limited resources meant that teachers could not effectively discharge their duties. The private schools featured in the present research have much better infrastructure and facilities than those reported by Mavundutse et al but they remain a concern for their school leaders, who need the best possible facilities to appeal to parents in a declining private school market.

Chakacha et al (2014) examined the relationship between infrastructure and learner outcomes, linked to concerns about escalating primary school drop-out rates and limited access to both technical and vocational education. This study was conducted in two primary schools in Zimbabwe, one public and one private, with 52 participants; 20 learners and 32 educators. The authors found that a well-equipped school is more functional and presents better learning opportunities for learners. This view connects to the concerns of the present authors' interviewees, who were worried that declining fee income meant that they could not develop school infrastructure to produce a better learning environment. The head of school F, for example, noted that:

We have limited laboratory space. Our labs are not up to standard to accommodate the number of the students that we have and then besides that the equipment for the key science subjects, talk of biology we need microscopes, we need some incubators. We don't have enough. The kids are not able to compete equitably in a global economy because of a poorer academic experience. 


\section{Relationships}

Relationships are frustrating for some participants. The head of school CM does not enjoy teacher-student problems, for example classroom management, especially where teachers lose control and fail to instill discipline in students. He adds, controversially, that this is a more serious problem with female teachers. He discusses:

'situations where teachers encounter problems with some students, where some teachers fail to discipline kids, where they fail to properly manage their classes so that they can have proper delivery of lessons. In certain situations, the lady teachers especially face a lot of those problems, with both male and female students'.

The head of school SP does not enjoy conflict (with parents and teachers), but adds that there are "not many problems'. The head of TP finds HR issues challenging including, for support staff, the involvement of unions. The head of school B thinks that it is 'a bit unfair' that 'the buck stops with me' and he does not enjoy disciplining students and teachers. The head of school T regrets the "weak family structures' and certain behavioural challenges, including drug abuse.

The teacher relationships' issues appear to be modest compared to those facing staff in the public sector. Chireshe and Shumba (2011) investigated why Zimbabwean teachers seem to be demotivated, drawing on a small (62) sample of primary school teachers on the Bachelor of Education in-service programme at a university in Zimbabwe. The authors found that motivation was adversely affected by low salaries, poor working conditions, poor accommodation, lack of respect, and overwork, among other factors. These challenges have resulted in low morale, poor delivery and a brain drain. This connects to Wadesango's (2010) study of teacher participation in decision-making in Zimbabwean secondary schools. He found that teacher participation is 'insignificant', despite their 'eagerness' to be involved. Greater participation is likely to increase teacher motivation.

The head of school F says that he finds the reporting structure, to the Church Board of Governors, 'difficult' and feels that he needs more clarity. This links to Chikoko's (2007: 22) multi-site case study of stakeholder involvement in public schools. They report that decentralised school governance has developed a sense of ownership of schools among stakeholders, but add that they seem incapable of functioning effectively within such a system. Their findings imply a need for greater capacity building of stakeholders, a suggestion that may also be helpful in the private sector.

The Christian ethos of most of these schools created relationship tensions for these leaders, notably in respect of parents. Some parents enrolled their children at school F, for example, due to its Christian 
values and environment, and a consequent high level of discipline. However, if teachers, parents and children failed to fit in, they would normally be left on their own:

'This being a Christian institution we have our culture where prayer is our daily bread. So sometimes it is a challenge to meet a school kid who doesn't seem appreciative of the need of prayer or a member of staff who doesn't seem to value prayer'.

\section{The Impact of the Economy on Student Numbers and School Leadership}

As noted above, the participating leaders used several strategies to manage the impact of Zimbabwe's economic problems, and the consequential, often precipitous, decline in student numbers. These include not replacing departing teachers and, in some cases, making teachers redundant. Many principals and senior leaders are also classroom teachers, so that they would not need to hire an additional teacher. Participants noted the challenges of keeping the remaining staff happy, and focused on good practice, in the face of lower salaries and dwindling resources. There were problems arising from staff supplementing their salaries, for example through second jobs, thus compromising the quality of education offered to the students.

The severe economic downturn has also impacted on schools' ability to secure adequate resources. Participants reporting having limited text books, few laboratories, and inadequate resources, including a lack of microscopes and of incubators for biology laboratories. Most leaders are also postponing decisions to enhance school facilities, albeit reluctantly, as they recognise that the school environment and infrastructure can be significant in attracting parents and students. The decision to cut fees, adopted at most of the schools, appears to be a desperate measure to retain students in order to survive in a difficult market for private education. While this may help to retain some students, it may not serve to stem the large fall in fee income. However, their motivation for fee reductions may have a moral basis, with the leaders clearly committed to supporting their students' continuing education, and doing all they can to keep them at school despite financial hardship.

Participants also reported that, as well as fee reductions, the more established schools have relaxed their formerly stringent recruitment procedures. Where there were previously multiple interviews, with applicants and their parents, the current primary focus is on parents' inability to pay. For example, the head of school CM highlighted the recruitment problems, noting that 'they used to interview. The pupils would have to go through four interviews. The parents would also go through two interviews. Now they have stopped all that. They only have one requirement - the ability to pay'. 
In some of the schools, many students were sponsored by the companies employing their parents but, due to the economic downturn, those allowances have been removed, leading to these children being withdrawn from private schools.

\section{Conclusion}

This overview of leadership in Zimbabwe's private schools shows the serious challenges involved in providing private education at a time when there are major problems for the Zimbabwean economy. The twelve schools in our sample are almost all experiencing falling enrolments, which most are trying to arrest by cutting fee levels. However, the combined impact of fewer students and lower fees has led to serious problems for the leadership and operation of these schools. There have been redundancies at several schools, which the leaders find stressful, while salary levels remain modest, although still higher than those in the public sector. The infrastructure and facilities are generally good compared to those in public schools but leaders lament that they cannot be enhanced in the current financial climate.

The authors' enquiry focused on the nature of satisfaction and dissatisfaction for these private school leaders, with the first two research questions focused directly on these issues. The most satisfying parts of the leaders' role were those relating to their professional role, notably classroom practice, instructional leadership and teacher development. Conversely, the least satisfying aspects related to the uncomfortable consequences of responding to the impact of economic decline on parents' ability to pay, leading to falling pupil numbers. The third and fourth research questions both address this issue directly. While the leaders tried to keep pupils in their schools for as long as possible, it was inevitable that non-payment of fees would lead to many of them leaving the school, and to what were often significant reductions in fee income. The other difficult consequence was to retrench teachers, and to reduce purchases of equipment and materials, to cut costs.

Most of the case schools have a distinctive Christian ethos, a strong sense of moral purpose (Bezzina 2012), and a vision to provide the best possible education for their children. However, this vision remains only partly fulfilled as the leaders' ambitious plans were thwarted by Zimbabwe's harsh economic realities. Sergiovanni's (1991) comment about the tensions involved in aligning moral and managerial leadership apply in an acute form in these Christian private schools. The 'moral dilemmas' (Rintoul and Goulais 2010) relate to both students and teachers. Allowing, or requiring, children to leave the schools, because of unpaid fees, was very uncomfortable for these leaders, who felt committed to learners' ongoing education, but did not have the resources to retain these students. Similarly, the leaders were very unhappy about retrenching teachers but this was also inevitable to balance the books. It was also often necessary to recruit students whose parents did not share the Christian values of the school, to 
address falling rolls. Managing the consequences of Zimbabwe's economic problems, a pragmatic approach, conflicted with the leaders' spiritual values, notably in terms of developing and maintaining Christian communities, leading to great discomfort for the participants. A significant improvement in the Zimbabwean economy is required to alleviate these dilemmas.

\section{References}

Bezzina, M. (2012), Paying attention to moral purpose in leading learning: Lessons from the Leaders Transforming Learning and Learners' project, Educational Management Administration and Leadership, 40 (2): 248-271.

Chabaya, O., Rembe, S. and Wadesango, N. (2009), The persistence of gender inequality in Zimbabwe: factors that impede the advancement of women into leadership positions in primary schools, South African Journal of Education, 29 (2): 235-251.

Chakacha, R.E., Iwu, C.G. and Dakora, E.N. (2014), Determining the relationship between infrastructure and learner success: A comparative study of two primary schools in Zimbabwe, Commonwealth Youth and Development, 12 (1): 15-32.

Chikoko, V. (2007), Negotiating roles and responsibilities in the context of decentralised school governance: A case study of one cluster of schools in Zimbabwe, International Studies in Educational Administration, 35 (1): 22-40.

Chiome, C. and Paul, M. (2011,) Zimbabwe in transition: Rethinking the school leadership conditions fostering transition, International Handbook of Leadership for Learning, 25: 1143-1167

Chireshe, R. and Shumba, A. (2011), Teaching as a profession in Zimbabwe: Are teachers facing a motivation crisis? Journal of Social Sciences, 28 (2): 113-118

Day, A., Mcloughlin, C., Aslam, M., Engel, J., Wales, J., Rawal S., Batley, R., Kingdon, G., Nicolai S., and Rose, P. (2014), The Role and Impact of Private Schools in Developing Countries: A Rigorous Review of the Evidence, Final Report, London, Department for International Development.

Keddie, A. (2016), School autonomy as the way of the future: Issues of equity, public purpose and moral leadership, Educational Management Administration and Leadership, 44 (5): 713.727.

Korb, K.A., Selzing-Musa, G. and Skinner-Bonat, S.B. (2016), The effect of training on teachers' knowledge of effective classroom strategies in Jos Metropolis, Global Journal of Educational Research, 15(1): 79-87.

Leithwood, K, Jantzi, D. and Steinbach, R. (1999), Changing Leadership for Changing Times, Buckingham, Open University Press.

Mapfumo, C. (2010), Private schools boom in Zimbabwe, African Business Review, 369: 50-51 
Masuku, S. (2011), The instructional leadership role of the high school head in creating a culture of teaching and learning in Zimbabwe, Unpublished Thesis, University of South Africa, <http://hdl.handle.net/10500/7741>

Mavundutse,O.,Munetsi,C., Attwell,M., Mavhunga, P..J., Kangai, P. and Gatsi, R. (2013) Emerging teacher education needs as a result of land reform in Zimbabwe: a focus on new resettlement areas, Academic Research International, 3 (2): 298-305

Moyo, S. (2014), Corruption in Zimbabwe: an examination of the roles of the state and civil society in combating corruption, Unpublished Ph.D. thesis, University of Central Lancashire.

Mupa, P. and Chinooneka, T. (2015), Factors contributing to ineffective teaching and learning in primary schools: Why are schools in decadence?, Journal of Education and Practice, 6: 125-132.

Pedzisai, C., Tsvere, M. (2013), Debtors Management in Gokwe East Cluster Day Secondary Schools, Gokwe South District, Zimbabwe, Journal of Education and Practice, 4 (23): 104-109 [Is this really issue 23 of volume 4 , or is it $23(4)$ ?]

Rintoul, H. and Goulais, L. (2010), Vice principalship and moral literacy: Developing a moral compass, Educational Management Administration and Leadership, 38 (6): 745-757.

Sergiovanni, T. (1991), The Principalship: A Reflective Practice Perspective, Needham Heights, MA, Allyn and Bacon

Simbarashe, M. and Edlight, M. (2011), Exploring the practice of "Extra" Lessons as offered in Chinhoyi Urban Secondary Schools, Mashonaland West Province, Zimbabwe, Journal of Innovative Research in Management and Humanities, 2 (1) 26-35.

Wadesango, N. (2010), The extent of teacher participation in decision-making in secondary schools in Zimbabwe, School Leadership and Management, 30 (3): 265-284.

West-Burnham, J. (1997), Leadership for learning: Re-engineering 'mind sets', School Leadership and Management, 17 (2): 231-243.

Woods, G. (2007), The 'bigger feeling': The importance of spiritual experience in educational leadership, Educational Management, Administration and Leadership, 35 (1): 135-155.

Zikhali, J. and Perumal, J. (2016), Leading in disadvantaged Zimbabwean school contexts, Educational Management Administration and Leadership, 44 (3): 347-362.

Zimeye (2009), Comment: Zimbabwe Education Sector faces Challenges, 16-9-2009 